\section{SOI: $1.1 / \mathrm{TAS} \quad$ DOI: $10.15863 / \mathrm{TAS}$ \\ International Scientific Journal Theoretical \& Applied Science}

\author{
p-ISSN: 2308-4944 (print) e-ISSN: 2409-0085 (online) \\ Year: 2015 Issue: 10 Volume: 30
}

Published: $30.10 .2015 \quad \underline{\text { http://T-Science.org }}$

SECTION 31. Economic researches, finance, innovations, risk management.
Natalia Vladimirovna Batciun

Associate Professor,

Department of World Economy,

Irkutsk National Research Technical University nbatsun@mail.ru

Tatyana Andreevna Zvonareva Master,

Department of Mineral processing and engineering Ecology, Irkutsk National Research Technical University tatyana.zvonareva@bk.ru

\title{
ECOLOGICAL AUDIT AS AN ELEMENT OF THE ENVIRONMENT PROTECTION SYSTEM AND RATIONAL NATURAL RESOURCES USAGE
}

\begin{abstract}
Ecological audit is a component of the mechanism of the management of environment considering providing the property rights, is important for economy as allows reducing the environmental, information and commercial risk connected with adoption of economic decisions. Ecological audit provides an independent assessment of observance with business of ecological requirements.

Key words: managements of environment, ecological audit, ecological legislation, complex assessment.

Language: Russian

Citation: Batciun NV, Zvonareva TA (2015) ECOLOGICAL AUDIT AS AN ELEMENT OF THE ENVIRONMENT PROTECTION SYSTEM AND RATIONAL NATURAL RESOURCES USAGE. ISJ Theoretical \& Applied Science 10 (30): 40-44 .

Soi: http://s-o-i.org/1.1/TAS-10-30-11 Doi: crossef http://dx.doi.org/10.15863/TAS.2015.10.30.11 \section{РАЦИОНАЛЬНОГО ПРИРОДОПОЛЬЗОВАНИЯ}

ЭКОЛОГИЧЕСКИЙ АУДИТ КАК ЭЛЕМЕНТ СИСТЕМЫ ОХРАНЫ ОКРУЖАЮЩЕЙ СРЕДЫ И

Аннотация: Экологический аудит является составной частью механизма управления окружающей средой, учитывающего обеспечение прав собственности, важен для экономики, так как позволяет уменьшить экологический, информационный и коммерческий риск, связанный с принятием хозяйственных решений. Экологический аудит обеспечивает независимую оценку соблюдения бизнесом экологических требований.

Ключевые слова: управления окружающей средой, экологический аудит, экологическое законодательство, комплексная оценка.

Экологический аудит является неотъемлемой составной частью механизма управления окружающей средой и природопользования, учитывающего обеспечение прав собственности, чрезвычайно важен для экономики, так как позволяет уменьшить экологический, информационный и коммерческий риск, связанный с принятием хозяйственных решений. Экологический аудит обеспечивает независимую, комплексную, документированную оценку соблюдения юридическим лицом или индивидуальным предпринимателем требований, в том числе нормативов и нормативных документов, в области охраны окружающей среды, требований международных стандартов и подготовки

рекомендаций по улучшению такой деятельности (ст.1 Федерального закона от 10.01.2002 г. № 7Ф3 «Об охране окружающей среды»). Так же он является важным источником информации для местных и региональных органов управления и обеспечивает реализацию цели по выработки рекомендаций эффективного использования ресурсов и обеспечения качества окружающей среды. Данный вид деятельности помогает выявить прошлые, существующие и предотвратить будущие экологические проблемы. Конечный этап экологического аудита - это выработка рекомендаций по снижению негативного воздействия на окружающую среду. Экологический аудит может проводиться перед экологической экспертизой, экологическими и
\end{abstract}


санитарно-эпидемиологическими проверками. Выполненный экологический аудит может способствовать успешному прохождению этих процедур, хотя и не может их заменить [1].

В настоящее время роль и место экологического аудита в системе государственного управления в области охраны окружающей среды РФ законодательно не установлены, что влечет неуправляемое его развитие в системе природоохранных услуг, и такое развитие не обеспечивает решение природоохранных государственных задач и достижение положительного экологического эффекта в деятельности предприятий.

Необходимость нормативно-правового обеспечения по регулированию экологической аудиторской деятельности уже длительное время обсуждается. Прежде всего, это вопросы экономической и экологической эффективности проведения экологического аудита для бизнеса.

Ведь именно экологический аудит позволит проводить независимую оценку природоохранной деятельности организации, выявить факты и причины нарушений в области охраны окружающей среды, что немаловажно и для самих предприятий как с целью предотвращения штрафных санкций так и с целью сохранения конкурентоспособности.

Одним из обязательных условий должно быть требование к руководителю аудиторской группы по приобретению дополнительного опыта по аудиту, обязательное совершенствование знаний и навыков, описанных в п.7.2.3.4 ГОСТ Р ИСО 19011-2012. Этот дополнительный опыт должен накапливаться и самой группой при исполнении обязанностей под руководством и наблюдением руководителя группы по аудиту (п.7.2.5 ГОСТ Р ИСО 190112012) [2].

Основы государственной политики в области экологического развития Российской Федерации на период до 2030 года, утвержденные Президентом РФ 30.04.2012 г., выделяют экологический аудит как один из путей решения задач развития экономического регулирования и рыночных инструментов охраны окружающей среды. Законопроект, разработанный Минприроды «Об экологическом аудите и экологической аудиторской деятельности», включает в себя четкое определение данного вида деятельности. Он разработан в целях реализации положений Государственной программы Российской Федерации «Охрана окружающей среды». В рамках проекта экологический аудит делится на аудит обязательный и добровольный. В законопроекте приведен закрытый перечень случаев, в которых необходимо проводить обязательный экологический аудит, также закреплена периодичность проведения. Вступление в силу новых норм предполагается с 1 января 2017 года, за исключением положений об обязательном и добровольном аудите, которые будут действовать только с 1 января 2019 года [3].

К основным принципам экологического аудита относят:

- презумпция

потенциальной экологической опасности любой намечаемой хозяйственной и иной деятельности;

- комплексность оценки воздействия на окружающую природную среду хозяйственной и иной деятельности и его последствий;

- обязательность учета требований экологической безопасности;

- достоверность и полнота информации;

- независимость экспертов при осуществлении ими своих полномочий;

- научная обоснованность, объективность и законность заключений экологического аудита;

- гласность, участие общественных организаций (объединений), учет общественного мнения;

- ответственность участников экологического аудита и заинтересованных лиц за организацию, проведение, качество процесса.[4]

К основным видам экологического аудита относятся:

1. Аудит соответствия - определение соответствия хозяйственной деятельности предприятия природоохранному законодательству.

2. Аудит управления - оценка эффективности управления, соответствия сформированной внутренней системы управления и корпоративной политики, установление степени экологического риска, связанного с деятельностью предприятия.

3. Аудит снабжения - оценка экологической безопасности сырья, материалов и оборудования, используемых при производстве продукции; выявление альтернативных ресурсосберегающих технологий, способствующих, кроме того, снижению себестоимости товара.

4. Аудит недвижимости - оценка прошлого экономического ущерба от загрязнения, а также потенциальной экологической ответственности.

5. Аудит обращения с отходами - оценка опасности отходов производства путем рекуперации, утилизации, размещения и захоронения.

6. Аудит энергопотребления - оценка энергопотребления и возможных путей его снижения. 
7. Аудит энергопотребления - оценка энергопотребления и возможных путей его снижения.

8. Стратегический аудит - оценка перспективной стратегии бизнеса с учетом экологических характеристик предприятия и выявления потенциальных деловых партнеров с экологически ориентированной системой управления.

9. Страховой экологический аудит - оценка риска и размера ущерба в результате возможных техногенных аварий, технологических сбоев, стихийных природных процессов и т. п. для обоснования и осуществления экологического страхования.

10. Аудит накопленных ущербов - оценка экологической опасности за прошлые накопленные ущербы на предприятии или объекте при переходе на другой вид собственности.

11. Инвестиционный экологический аудит оценка необходимых затрат на экологические аспекты деятельности при инвестировании в реконструкцию,

расширение, перепрофилирование, при закрытии предприятия [5].

Процедура экологического аудита должна осуществляться предпочтительнее третьей стороной для обеспечения независимости и объективности аудиторского исследования. Но в аудиторскую группу также могут быть включены представители аудируемого предприятия [6].

Рассмотрим подробно основные этапы экологического аудита, обеспечивающие его эффективность.

1-й этап. Организация проведения аудита.

- Установление первоначального контакта с проверяемой организацией (п.6.2.2 ГОСТ Р ИСО 19011-2012).

Может иметь официальный или неформальный характер. Целями первоначального контакта могут являться: установление связи и каналов передачи информации с представителями проверяемой организации; подтверждение полномочий для проведения аудита; получение доступа к соответствующей документации.

- Определение возможности проведения аудита (п.6.2.3 ГОСТ Р ИСО 19011-2012).

Нужно определить возможность проведения аудита, достаточность информации для планирования аудита, адекватное содействие и сотрудничество со стороны проверяемой организации, достаточность времени и ресурсов для выполнения аудита.

- Выполнение анализа документов при подготовке к аудиту (п.6.3.1 ГОСТ Р ИСО 190112012).
Необходимо

проанализировать документацию соответствующей системы менеджмента проверяемой организации. Собрать информацию для подготовки мероприятий аудита. Осуществить обзор документации системы для выявления возможных пробелов.

- Подготовка плана аудита (п.6.3.2 ГОСТ Р ИСО 19011-2012).

Руководителю группы по аудиту следует подготовить план аудита, основанный на информации, содержащейся в программе аудита, и документации, предоставленной проверяемой организацией.

- Распределение работ между членами группы по аудиту (п.6.3.3 ГОСТ Р ИСО 190112012).

- Подготовка рабочих документов (п.6.3.4 ГОСТ Р ИСО 19011-2012).

Члены группы по аудиту должны собирать и анализировать информацию, относящуюся к зоне их ответственности, и осуществлять подготовку рабочих документов надлежащим образом для фиксации и протоколирования свидетельств аудита.

2-й этап. Подготовка к проведению аудита на месте.

- Проведение предварительного совещания (п.6.4.2 ГОСТ Р ИСО 19011-2012).

3-й этап. Отчета по аудиту.

- Подготовка отчета по аудиту (п.6.5.1 ГОСТ Р ИСО 19011-2012).

Руководитель группы по аудиту несет ответственность за подготовку и содержание отчета по аудиту. Отчет по аудиту должен содержать полные, точные, четко сформулированные и понятные записи по аудиту в соответствии с процедурами аудита.

- Рассылка отчета по аудиту (п.6.5.2 ГОСТ Р ИСО 19011-2012).

Отчет по аудиту должен быть подготовлен и представлен в согласованные сроки.

4-й этап. Завершение аудита.

Аудит считается завершенным, если все запланированные мероприятия аудита были выполнены или же на основании, согласованном c заказчиком аудита. Например, могут быть непредвиденные ситуации, которые препятствуют тому, чтобы аудит был завершен в соответствии с разработанным планом (п.6.6 ГОСТ Р ИСО 19011-2012).

5-й этап. Действия по результатам аудита.

Заключения по результатам аудита могут в зависимости от целей аудита указывать на необходимость выполнения коррекций, корректирующих и предупреждающих действий или действий по улучшению. При необходимости проверяемой организации следует информировать лицо, ответственное за управление программой аудита, и группу 
аудиторов о состоянии выполнения этих действий (п.6.7 ГОСТ Р ИСО 19011-2012).

Данные этапы применимы не только к экологическому аудиту предприятия, но и аудиту систем экологического менеджмента, так как они не устанавливают жестких рамок и допускают гибкость в своем применении. Применение этапов согласно ГОСТ Р ИСО 19011-2012 может различаться в зависимости от размера, уровня развития и совершенства системы экологического менеджмента организации, от характера деятельности и сложности проверяемого предприятия, а также от целей и области применения проводимых аудитов [7].

В феврале 2015 года в г. Ялта (Республика Крым) состоялась Конференция «Экологический аудит - новая роль в области охраны окружающей среды».

В ходе конференции были освещены вопросы экономической и экологической эффективности проведения экологического аудита для бизнеса, современных тенденции и опыта международной практики проведения экологического аудита, разработки законопроектов об экологическом аудите, экологической аудиторской деятельности, вопросы проведения экологического аудита при осуществлении деятельности по обезвреживанию отходов I - III классов опасности, а также системы подготовки, повышения квалификации, аттестации и аккредитации экологических аудиторов и др. Наиболее спорным вопросом оказался вопрос о сопоставимости государственного экологического надзора и экологического аудита.[8]

В рамках этой конференции выступили представители Минприроды России, Общественной палаты Российской Федерации, Росприроднадзора, АНО «Единая аттестационная комиссия» при Минфине России, Минэнерго России, Высшей школы экономики, АНО «Национальная промышленно-экологическая Палата», НП «Национальная экологическая аудиторская палата», Гильдии российских адвокатов, а также научного и бизнес сообществ. Отмечено, что экологический аудит в отличие от государственного экологического надзора не предполагает проверки соблюдения хозяйствующим субъектом требований в области охраны окружающей среды и не сопровождается наложением штрафных санкций, представляя собой независимую оценку соответствия объектов экологического аудита требованиям в области охраны окружающей среды.

По результатам пленарных заседаний участниками Конференции рекомендовано при доработке законопроектов «Об экологическом аудите и экологической аудиторской деятельности» и «О внесении изменений в отдельные законодательные акты Российской Федерации в связи с принятием Федерального закона «Об экологическом аудите и экологической аудиторской деятельности» рассмотреть следующие предложения:

- о возможности упрощенного порядка получения квалификационного аттестата экологического аудитора аудиторами, имеющими действующий аттестат и многолетний опыт такой деятельности;

- о возможности применения к деятельности юридических лиц и индивидуальных предпринимателей по проведению экологического аудита мер государственной поддержки;

- о праве экологических аудиторских организаций при проведении экологического аудита требовать и получать у аудируемого лица финансовые и иные документы, необходимые для проведения экологического аудита;

- о независимости аттестационной комиссии экологического аудита;

- о создании при Минприроды России совета по экологической аудиторской деятельности;

Участниками Конференции поддержана замена случая обязательного экологического аудита при осуществлении деятельности по обезвреживанию отходов I-III класса опасности на утилизацию отходов I-III класса.[9]

Заключения российских экологов-аудиторов чаще всего используются хозяйствующими субъектами для формирования собственной экологической политики и определения приоритетов природоохранной деятельности, что значительно ограничивает потенциальные возможности использования экологического аудита.

Вот некоторые из таких возможностей:

- идентификация ранее не учтенных источников воздействия на окружающую среду и отходов;

- оптимизация потребления ресурсов; - обоснование целесообразности проведения дополнительных изысканий и НИОКР; - появление дополнительной продукции, услуг, вторичного сырья и энергетических ресурсов; - обоснование и сравнение альтернативных вариантов, предложений по внедрению новой техники, природоохранных и других мероприятий;

- оценка дополнительных капитальных и производственных затрат по вариантам решений и срокам их окупаемости: - определение вероятных источников финансирования (долевого участия предприятий в строительстве или реконструкции очистных сооружений и систем размещения и удаления 
отходов);

- изменение платежей за выбросы и сбросы и размещение отходов, за использование природных ресурсов, за сбросы в городскую канализацию;

- возможное уменьшение или исключение существующих и снижение риска возникновения дополнительных штрафных санкций и экологоэкономической ответственности (возмещение ущербов);

- определение дополнительных затрат на развитие системы мониторинга и производственного экологического контроля; - изменение затрат на эксплуатацию систем регулирования воздействия на окружающую среду (например отказ от использования опасных веществ);

- изменение затрат и возможная прибыль, связанные с появлением дополнительной продукции. [10]

Отсутствие государственного регулирования экологического аудита в России не позволяет государству в полном объёме применять возможности экологического аудита. Мировой опыт свидетельствует, что экологическое аудирование имеет значение, если оно проводится, прежде всего, как добровольная не государственная деятельность

(«инициативный аудит»).[11]

Сертификация на соответствие стандартам, признанным не только в России, но и за рубежом, имеет существенное значение для активного развития и повышения уровня конкурентоспособности компаний. Интегрированная система менеджмента (ИСМ) наиболее оптимально позволяет выполнить требования по повышению уровня экологичности, безопасности, качества товаров и услуг, обеспечивает согласованность и структурированность действия внутри организации.

Проверка природоохранной отчетности предприятий имеет здесь вторичное значение. Главное же - это аудиторские рекомендации и предложения по улучшению эффективности и инициированию природоохранной деятельности предприятия, развитию системы экологического контроля и управления.

Именно поэтому экологический аудит должен развиваться в нашей стране и во всем мире, как один из методов предупреждения изменений окружающей среды и предотвращения катастрофы [12].

\section{References:}

1. Grinin AS, Orexov NA, Shmidxejni S (2011) Ekologicheskij menedzhment, YUNITI-DANA, 2011.

2. Kachalov VA (2010) Kak mezhdunarodnaya organizaciya po standartizacii mozhet pomoch' Rossii v reshenii ee e'kologicheskix problem, NTK «Trek». Nauchno-texnicheskij sbornik «Ves o kachestve. otechestvenny'e razrabotki», 2010.

3. (2015) Spravochnik E'kologa. Available: http://www.profiz.ru/eco/news/2/news_audit/ (Accessed: 02.10.2015).

4. (2015) E'kologicheskij Konsalting Http://Omnieco.Ru/Uslugi/EkologicheskijAudit.Html (Accessed: 02.10.2015).

5. Paxomova NV, E'nders A, Rixter K (2013) E'kologicheskij menedzhment, Piter», 2013.

6. Trifonova TA, Selivanova NV, Il'ina ME (2013) E'kologicheskij menedzhment, Akademicheskij proekt: Fond «Mir», 2013.

7. Belov GV (2012) E'kologicheskij menedzhment predpriyatiya, «Logos», 2012.

8. (2015) Konferenciya «E'kologicheskij audit novaya rol' v oblasti oxrany' okruzhayushhej sredy'»).

Available: http://www.mnr.gov.ru/activities/list.php?part= 1729 (Accessed: 02.10.2015).

9. (2015) Rezolyuciya Konferencii «E'kologicheskij audit - novaya rol' v oblasti oxrany' okruzhayushhej sredy'» (12 - 13 fevralya 2015 g. g. Yalta, Respublika Kry'm). Available:

http://www.mnr.gov.ru/activities/detail.php?ID $=139618$ (Accessed: 02.10.2015).

10. Filobokova LY (2008) E'kologicheskij audit: metodicheskie podxody' $\mathrm{k}$ upravleniyu i ocenke e'ffektivnosti prirodooxrannoj politiki // E'konomicheskij analiz: teoriya i praktika. 2008. № 17.

11. (2013) E'kologicheskij audit. Teoriya I praktika: uchebnik dlya studentov vuzov / [i.m. Potravny'j i dr.]; pod red. i.m. Potravnogo. - M.: YUNITI-DANA, 2013. - (Seriya «Magister»).

12. Vasil'evskij IV (2010) E'kologicheskij menedzhment, «Piter», 2010. 